\title{
0 papel dos desreguladores endócrinos na fisiopatologia da endometriose: revisão da literatura
}

\author{
The role of the endocrine disruptors in the physiopathology of endometriosis: \\ review of literature
}

Bianca Bianco', Denise Maria Christofolini', Ângela Mara Bentes de Souza', Caio Parente Barbosa'

\section{Resumo}

0 efeito prejudicial que os desreguladores endócrinos podem ter na saúde humana está chamando a atenção da comunidade científica. Essas substâncias são capazes de mimetizar, bloquear ou modular a resposta endócrina por meio da interação com os receptores dos hormônios esteroides e incluem substâncias como pesticidas, fungicidas, dioxinas, ftalatos, bisfenol A, fitoestrogênios, entre outros. A endometriose é uma doença ginecológica comum, que acomete cerca de $15 \%$ das mulheres em período reprodutivo e $50 \%$ das mulheres com problemas de fertilidade. Muitas teorias foram propostas para tentar explicar o desenvolvimento das lesões. Todavia, não existe, até o momento, uma teoria única que identifique e explique todos os aspectos clínicos dessa doença considerada multifatorial. Recentemente, contaminantes ambientais têm sido implicados na fisiopatologia da endometriose. Este trabalho teve por objetivo realizar uma revisão crítica da literatura médica sobre a influência de compostos ambientais no desenvolvimento da endometriose.

Palavras-chave: Endometriose; disruptores endócrinos; exposição ambiental.

\begin{abstract}
The hazardous effects that endocrine disruptors may have on human health have attracted the attention of scientific community. These chemicals have the capacity to mimic, block or modulate the endocrine response by the means of the interaction with steroidal receptors. Endocrine disruptors include substances such as pesticides, fungicides, dioxins, phthalates, bisphenol A, phytoestrogens and others. Endometriosis is a common gynecological disease affecting about $15 \%$ of women in reproductive ages and $50 \%$ of women with fertility problems. Several theories have been proposed to explain the development of the lesions. However, at present, there is not a single theory to identify and explain all clinical aspects of this multifactorial disease. Recently, environmental contaminants have been involved in the physiopathology of endometriosis. The aim of this work was a critic medical literature review about the influence of environmental contaminants on endometriosis development.
\end{abstract}

Keywords: Endometriosis; endocrine disruptors; environmental exposition.

Recebido: $18 / 9 / 2009$

Revisado: 3/11/2009

Aprovado: $13 / 11 / 2009$

\footnotetext{
Disciplina de Ginecologia Patológica e Reprodução Humana do Departamento de Ginecologia e Obstetrícia da Faculdade de Medicina do ABC (FMABC), Santo André (SP), Brasil

Endereço para correspondência: Bianca Bianco - Faculdade de Medicina do ABC - Prédio Cepes - Avenida Príncipe de Gales, $821,2^{\circ}$ andar -

CEP 09060-650 - Santo André (SP) - E-mail: bianca.bianco@hotmail.com
} 


\section{Introdução}

As funções do corpo são reguladas por dois grandes sistemas de controle: o sistema nervoso e o sistema endócrino. Cada órgão que compõe o sistema endócrino segrega um tipo de hormônio que tem efeito regulador em outros órgãos a distância ${ }^{1}$. Existem muitas inter-relações entre os sistemas endócrino e nervoso. Por exemplo, pelo menos duas glândulas secretam seus hormônios quase que inteiramente em resposta a estímulos neurais: as medulas suprarrenais e a glândula hipofisária. Os órgãos que pertencem ao sistema endócrino são os testículos, os ovários, o pâncreas, as glândulas suprarrenais, a tireoide, a paratireoide, a pituitária e o tálamo․ Tanto em humanos como em animais, a sinalização endócrina está envolvida na reprodução, desenvolvimento embrionário, crescimento, maturação, produção de energia, uso e estoque de energia e balanço eletrolítico. Os hormônios executam tais funções pela interação com seus receptores, que estão presentes tanto no núcleo como na superfície das células, em vários órgãos e tecidos como parte de um sistema biológico complexo de retroalimentação. Qualquer desregulação nesse balanço pode causar prejuízo fisiológico no organismo, principalmente durante os estágios iniciais do desenvolvimento, prejudicando a função e/ou o desenvolvimento do sistema reprodutivo, nervoso e imune. Numerosos compostos naturais e sintéticos podem interferir no eixo reprodutivo de mamíferos, resultando na diminuição da fertilidade, perdas gestacionais e aumento de doenças ginecológicas, como endometriose, puberdade precoce e câncer de mama e endométrio. Tais compostos são denominados desreguladores endócrinos $(\mathrm{DE})^{2,3}$.

\section{0 que é um desregulador endócrino?}

Um desregulador endócrino é uma substância exógena ou uma mistura de substâncias, naturais ou sintéticas, que podem danificar diretamente um órgão endócrino, alterar diretamente a função de um órgão endócrino, interagir com um receptor de hormônios ou alterar o metabolismo de um hormônio em um órgão endócrino e, consequentemente, causar efeitos adversos à saúde de um organismo, de sua prole, ou ainda de uma população ${ }^{4}$. Os DEs estão difundidos nas cadeias alimentares e no ambiente e incluem substâncias naturais e sintéticas, que podem ser agrupadas em duas classes: 1) substâncias sintéticas utilizadas na agricultura e seus subprodutos, como pesticidas, herbicidas, fungicidas e moluscicidas; substâncias utilizadas nas indústrias e seus subprodutos, como dioxinas, bifenilas policloradas (PCB), alquilfenóis e seus subprodutos, hidrocarbonetos aromáticos policíclicos (HAP), ftalatos, bisfenol A e metais pesados; compostos farmacêuticos, como os estrogênios sintéticos dietilestilbestrol (DES) e 17 $\alpha$-etinilestradiol; 2) substâncias naturais derivada de plantas - fitoestrogênios, tais como genisteína e metaresinol, e estrogênios naturais, como $17 \beta$-estradiol, estrona e estriol ${ }^{5}$ (Quadro 1).

A origem da hipótese da ação dos DEs deve-se a acontecimentos importantes, tais como o aparecimento de câncer no sistema reprodutivo de filhas de mulheres que usaram DES na gravidez, entre os anos de
1940 a $1970^{6}$; anomalias no sistema reprodutivo observadas em jacarés que habitavam em um lago na Flórida, Estados Unidos, contaminado com o pesticida diclorodifeniltricloroetano (DDT) e seu metabólito diclorodifenildicloroetileno (DDE) ${ }^{7}$.

No Brasil, recentemente, foram relatados alguns efeitos relacionados à exposição de desreguladores endócrinos no meio ambiente. Fernandez et al. ${ }^{8}$ relataram a exposição de organismos marinhos a compostos orgânicos contendo estanho, tributilestanho (TBT) e trifenilestanho (TPT) no litoral do Brasil (Rio de Janeiro e Fortaleza) e o desenvolvimento de caracteres sexuais masculinos em fêmeas de moluscos. Koifman et al. ${ }^{9}$ apresentaram os resultados de um estudo epidemiológico que relaciona a exposição a pesticidas durante os anos 1980 e distúrbios reprodutivos, tais como câncer de mama, ovário e próstata e diminuição das taxas de espermatozoides no ejaculado, observados nos anos 1990 em estados brasileiros (São Paulo, Paraná, Santa Catarina, Rio Grande do Sul, Bahia, Pernambuco, Espírito Santo, Minas Gerais, Mato Grosso, Mato Grosso do Sul e Goiás).

Substâncias derivadas de plantas também podem ser consideradas DEs, como os fitoestrógenos, que incluem também as isoflavonas, e estão presentes em alguns itens alimentares, como a soja, e em cosméticos com componentes ativos de origem vegetal. Uma boa dieta com fitoestrógenos pode ser protetora contra alguns tipos de cânceres, por exemplo, de mama e próstata, e também doenças da pós-menopausa, como a osteoporose; no entanto, devem ser utilizados com cautela durante a gravidez e na infância. Muitos desreguladores endócrinos são conhecidos por agirem como agonistas dos receptores estrogênicos, como o bisfenol A, ou como antagonistas dos receptores androgênicos, como o fungicida dicarboximida ${ }^{10}$.

Toneladas de substâncias sintéticas e naturais são lançadas anualmente no meio ambiente, das quais um número considerável é de DE. Além de serem associados aos efeitos no sistema endócrino, alguns são também persistentes, lipofílicos, bioacumulativos e têm baixa pressão de vapor, o que facilita a dispersão e difusão no meio ambiente ${ }^{11}$.

A exposição aos DEs pode ocorrer sob diferentes formas, como por meio do contato direto ocupacional e/ou domiciliar ou indireto, por meio da ingestão de água ou alimentos contaminados e o contato com o solo. No caso dos seres humanos, estima-se que mais de $90 \%$ dessas substâncias ambientais são absorvidas por via digestiva, principalmente por meio de alimentos contaminados ${ }^{12}$.

Alguns DEs são solúveis em gordura, assim, altos níveis podem estar presentes em carne, peixe, ovos e derivados do leite. Hartmann et al. ${ }^{13}$ relataram a ocorrência de hormônios sexuais (17 $\beta$-estradiol, estrona, testosterona e progesterona) em carnes (bovinos, suínos, aves e peixes), leite e seus derivados, ovos e plantas (gramíneas e leguminosas). A contaminação de alimentos também pode vir do fato de que alguns hormônios são aplicados na criação de animais e consumidos na alimentação humana. Contudo, em grande parte dos países essa prática está proibida ${ }^{14}$.

A exposição também pode vir de pesticidas residuais que contaminam frutas, vegetais e, em baixas concentrações, a água potável. Outras 
fontes de exposição direta dos alquilfenóis são por meio do uso de produtos pessoais, como maquiagem, cremes, produtos para cabelo e banho ${ }^{11}$.

\section{A endometriose}

A endometriose é uma inflamação crônica que representa uma das doenças ginecológicas benignas mais comuns ${ }^{15}$. A lesão endometrial é uma condição esteroide-dependente, na qual o tecido histologicamente similar ao endométrio, com glândulas e estroma, cresce fora da cavidade uterina, implantando-se em tecidos e órgãos, como as trompas, ová- rios, peritônio, cólon, a região retrovaginal e bexiga ${ }^{16}$, podendo causar dor pélvica, dismenorreia e infertilidade ${ }^{16}$. Estima-se que, aproximadamente, 10 a $15 \%$ das mulheres em período reprodutivo ${ }^{17,18}$, cerca de $40 \%$ das mulheres com dor pélvica e $50 \%$ das mulheres com problemas de fertilidade possuam essa doença ${ }^{15}$.

A endometriose foi observada, pela primeira vez, por Rokitansky, em 1869, em material de necrópsia. Desde então, muitas teorias foram propostas para tentar explicar o desenvolvimento das lesões. Von Recklinghausen, em 1896, e Russell, em 1899, propuseram a origem da endometriose pelas células embrionárias. Meyer, em 1919, postulou que a endo-

Quadro 1 - Algumas substâncias químicas classificadas como desreguladores endócrinos

\begin{tabular}{|c|c|c|c|}
\hline Composto químico & 0 que são & Meios de exposição & Mecanismo de ação \\
\hline Dioxinas & $\begin{array}{l}\text { São subprodutos de processos industriais, devido } \\
\text { à combustão incompleta de compostos orgânicos. } \\
\text { Incineradores que processam lixo municipal, resíduo } \\
\text { industrial ou material hospitalar, termoelétrica a } \\
\text { carvão, fábricas de papel e celulose, fumaça de } \\
\text { veículos automotores, cigarro, fornos de produção } \\
\text { de cimento e fundição de chumbo são fontes de } \\
\text { produção desse composto. Processos naturais, } \\
\text { como erupções vulcânicas e queimadas florestais, } \\
\text { são outras fontes desses produtos }\end{array}$ & $\begin{array}{l}\text { Alimentos (leite e derivados, peixes } \\
\text { etc.) } \\
\text { Meio ambiente }\end{array}$ & $\begin{array}{l}\text { Alteração no metabolismo dos } \\
\text { hormônios esteroides } \\
\text { Efeitos neuroendócrinos, } \\
\text { incluindo a tireoide }\end{array}$ \\
\hline Pesticidas & $\begin{array}{l}\text { São substâncias ou mistura de substâncias } \\
\text { utilizadas na produção, colheita ou no armazena- } \\
\text { mento de alimentos, capazes de prevenir, destruir } \\
\text { ou combater espécies indesejáveis que, de alguma } \\
\text { maneira, possam interferir na produção, processa- } \\
\text { mento, armazenamento, transporte e estocagem de } \\
\text { alimentos, produtos agrícolas em geral, madeira e } \\
\text { produtos derivados de madeira }\end{array}$ & $\begin{array}{l}\text { Alimentos (principalmente vegetais) } \\
\text { Meio ambiente } \\
\text { Áreas agrícolas }\end{array}$ & $\begin{array}{l}\text { Inibidor da síntese dos hormônios } \\
\text { esteroides } \\
\text { Efeitos no eixo hipotálamo- } \\
\text { hipofisário-gonadal }\end{array}$ \\
\hline Alquilfenóis & $\begin{array}{l}\text { São substâncias presentes em antioxidantes, poli- } \\
\text { estireno modificado, surfactantes e PVC }\end{array}$ & $\begin{array}{l}\text { Detergentes } \\
\text { Frutos do mar } \\
\text { Produtos industrializados }\end{array}$ & $\begin{array}{l}\text { Agonista estrogênico (receptor } \\
\text { estrogênico alfa) }\end{array}$ \\
\hline Bisfenol A & $\begin{array}{l}\text { Composto utilizado na fabricação de plásticos } \\
\text { policarbonatos e epóxi de resina, presente na resina } \\
\text { do forro de latas de alimento e bebida, e na com- } \\
\text { posição de material odontológico selante }\end{array}$ & $\begin{array}{l}\text { Alimentos } \\
\text { Plásticos em contato com a comida } \\
\text { Produtos industrializados (aditivos } \\
\text { plásticos, selantes dentários etc.) }\end{array}$ & $\begin{array}{l}\text { Agonista estrogênico (receptor } \\
\text { estrogênico alfa) }\end{array}$ \\
\hline Ftalatos & $\begin{array}{l}\text { Ftalatos são substâncias usadas para dar flexibili- } \\
\text { dade e durabilidade ao PVC }\end{array}$ & $\begin{array}{l}\text { Alimentos } \\
\text { Cosméticos } \\
\text { Brinquedos } \\
\text { Material médico-hospitalar } \\
\text { Roupas }\end{array}$ & $\begin{array}{l}\text { Agonistas do receptor de } \\
\text { Pregnano } \\
\text { Biossíntese dos esteroides } \\
\text { sexuais }\end{array}$ \\
\hline $\begin{array}{l}\text { Retardantes de chama } \\
\text { bromado }\end{array}$ & $\begin{array}{l}\text { São substâncias químicas utilizadas com o intuito } \\
\text { de diminuir o risco de incêndio ou minimizar o } \\
\text { dano causado por ignição. São relativamente } \\
\text { persistentes, lipofílicos, com tendência à bioacu- } \\
\text { mulação }\end{array}$ & $\begin{array}{l}\text { Alimentos (leite e derivados, peixes) } \\
\text { Meio ambiente } \\
\text { Equipamentos eletrônicos }\end{array}$ & $\begin{array}{l}\text { Alteração da homeostase dos } \\
\text { hormônios esteroides e tireoidi- } \\
\text { anos }\end{array}$ \\
\hline Parabenos & $\begin{array}{l}\text { São compostos utilizados como conservantes anti- } \\
\text { microbianos em produtos alimentícios, farmacêuti- } \\
\text { cos e cosméticos }\end{array}$ & $\begin{array}{l}\text { Cosméticos } \\
\text { Conservantes farmacêuticos }\end{array}$ & $\begin{array}{l}\text { Agonista estrogênico (receptor } \\
\text { estrogênico alfa e beta) }\end{array}$ \\
\hline Metais pesados & $\begin{array}{l}\text { Os metais pesados compreendem aqueles elemen- } \\
\text { tos cuja densidade excede } 5 \mathrm{~g} / \mathrm{cm}^{3} \text {. Os meios } \\
\text { aquáticos também são depósitos de uma variedade } \\
\text { de metais pesados e isso ocorre naturalmente por } \\
\text { meio de processos geoquímicos e intemperismo }\end{array}$ & $\begin{array}{l}\text { Alimentos (alimentos refinados, como } \\
\text { farinha, arroz, açúcar e frutos do mar) } \\
\text { Cigarros }\end{array}$ & $\begin{array}{l}\text { Agonista estrogênico (receptor } \\
\text { estrogênico alfa) }\end{array}$ \\
\hline Fitoestrógenos & $\begin{array}{l}\text { Fitoestrógenos são compostos derivados de plantas } \\
\text { com estrutura química e atividade hormonal semel- } \\
\text { hante ao estradiol }\end{array}$ & $\begin{array}{l}\text { Alimentos (vegetais e óleo de soja) } \\
\text { Cosméticos }\end{array}$ & $\begin{array}{l}\text { Modulador seletivo do receptor } \\
\text { estrogênico, alta afinidade com o } \\
\text { receptor estrogênico beta }\end{array}$ \\
\hline Protetores contra a luz UV & Substâncias que possuem estabilidade à luz UV & $\begin{array}{l}\text { Protetor solar } \\
\text { Cosméticos }\end{array}$ & $\begin{array}{l}\text { Agonista estrogênico (receptor } \\
\text { estrogênico alfa) }\end{array}$ \\
\hline
\end{tabular}

PVC: policloreto de vinila; UV: ultravioleta. 
metriose se originava de metaplasia das células epiteliais celômicas do peritônio. Halban, em 1924, sugeriu que a endometriose poderia se originar por disseminação de células endometriais pelo sistema linfático. E, finalmente, Sampons et al., em 1927, propuseram a menstruação retrógrada com subsequente implantação, crescimento viável e neovascularização de estruturas pélvicas como a teoria inicial da formação da endometriose ${ }^{19}$.

Corroborando a teoria da menstruação retrógrada, observa-se uma forte associação entre a endometriose e o fluxo menstrual obstruído que ocorre na presença de anormalidades müllerianas. A presença do refluxo menstrual anormal poderia irritar o peritônio que, para se defender, secretaria fatores de crescimento e ativação que poderiam facilitar a implantação e o crescimento e também induzir a metaplasia ${ }^{20}$.

Todavia, mais de $90 \%$ das mulheres em idade reprodutiva mostram, pelo menos, alguma menstruação retrógrada e nem todas apresentam endometriose ${ }^{16}$. Assim, até o momento, não existe uma teoria única que identifique e explique todos os aspectos clínicos dessa doença considerada multifatorial. Contaminantes ambientais têm sido implicados na fisiopatologia da endometriose ${ }^{21}$, uma vez que a exposição a poluentes ambientais tóxicos podem levar a modificação epigenética de genes críticos ${ }^{22}$, resultando em expressão gênica alterada (Quadro 2).

\section{A endometriose e os desreguladores endócrinos}

Estudos demonstraram que a exposição a TCDD (dioxina 2,3,7,8-tetraclorodibenzo-p-dioxina) está associada com o aumento da prevalência e a gravidade da endometriose $e^{21,23-25}$. A exposição hu- mana e animal a TCDD não só afeta níveis de receptores esteroides e a expressão gênica, mas também pode afetar o metabolismo dos hormônios esteroides e o transporte sérico ${ }^{26-28}$. O TCDD pode também modular a produção local e ação de citocinas endometriais, causando desregulação do sistema imunológico do trato reprodutivo pelo redirecionamento dos elementos do transporte e comportamentos dos leucócitos ${ }^{29-31}$. O rompimento da relação imune-endócrina potencialmente conduz ao aumento da sensibilidade endometrial às citocinas pró-inflamatórias, notável em pacientes com endometriose ${ }^{32}$.

Osteen et $a ._{.}^{32}$ e Igarashi et $a l_{.}^{33}$ demonstraram que a exposição de coculturas primárias de células adultas do estroma e epitélio endometrial ao TCDD diminuiu a relação da expressão do receptor de progesterona B (PR-B) e A (PR-A), PR-A/PR-B, nos fibroblastos do estroma e aumentou a expressão de metaloproteinases tanto no estroma como no epitélio endometrial. Além disso, a prole dos camundongos expostos ao TCDD demonstrou alteração na expressão de progesterona e desregulação da fertilidade por três gerações, sem exposição adicional a qualquer desregulador endócrino ${ }^{34}$, sugerindo uma herança da alteração epigenética ${ }^{35}$.

Assim, relacionado ou não à exposição a agentes desreguladores endócrinos, o endométrio de mulheres com endometriose exibe diminuição da sensibilidade à progesterona semelhante à observada em murinos $^{32,36,37}$. Dado o efeito anti-inflamatório da progesterona ${ }^{38,39}$, a redução da sensibilidade a esse esteroide poderia contribuir para a autoimunidade natural contra a endometriose, bem como para as alterações celulares específicas, locais e sistêmicas, que têm sido relatadas em pacientes com a doença $a^{40-44}$.

Quadro 2 - Estudos sobre os efeitos dos compostos desreguladores endócrinos na endometriose

\begin{tabular}{|c|c|c|c|}
\hline Autor & População Estudada & Composto & Conclusão do estudo \\
\hline Mayani et al..$^{50}$ & $\begin{array}{l}\text { Mulheres com endometriose e } \\
\text { controles }\end{array}$ & TCDD (dioxina) & Associação positiva entre a endometriose e a exposição à dioxina \\
\hline Lebel et al..$^{51}$ & $\begin{array}{l}\text { Mulheres com endometriose e } \\
\text { controles }\end{array}$ & TCDD (dioxina) & Nenhuma associação entre a endometriose e a exposição à dioxina \\
\hline Pauwels et al. ${ }^{23}$ & $\begin{array}{l}\text { Mulheres com endometriose e } \\
\text { controles }\end{array}$ & TCDD (dioxina) & $\begin{array}{l}\text { Aumento da endometriose associada com elevados níveis séricos } \\
\text { de dioxina e compostos derivados }\end{array}$ \\
\hline Yang et al., $2000^{24}$ & Macacos & TCDD (dioxina) & $\begin{array}{l}\text { Aumento da taxa de sobrevivência dos implantes e do tamanho dos } \\
\text { fragmentos endometrióticos }\end{array}$ \\
\hline Rier e Foster ${ }^{25}$ & Macacos & TCDD (dioxina) & $\begin{array}{l}\text { Níveis elevados de dioxina correlacionaram-se fortemente com a } \\
\text { endometriose }\end{array}$ \\
\hline Eskenazi et al., $2002^{49}$ & Mulheres italianas & TCDD (dioxina) & Nenhuma associação entre a endometriose e a exposição à dioxina \\
\hline Cobellis et al..$^{52}$ & $\begin{array}{l}\text { Mulheres com endometriose e } \\
\text { controles }\end{array}$ & DEHP (ftalato) & $\begin{array}{l}\text { Concentrações elevadas de DEHP no soro e no fluido peritoneal de } \\
\text { mulheres com endometriose }\end{array}$ \\
\hline Osteen et al..$^{32}$ & $\begin{array}{l}\text { Co-culturas primárias de células } \\
\text { adultas do estroma e epitélio } \\
\text { endometrial }\end{array}$ & TCDD (dioxina) & $\begin{array}{l}\text { Diminuição da expressão da progesterona nos fibroblastos do } \\
\text { estroma e aumento da expressão de metaloproteinases tanto no } \\
\text { estroma como no epitélio endometrial }\end{array}$ \\
\hline Nayyar et al. ${ }^{34}$ & $\begin{array}{l}\text { Prole de camundongos expostos } \\
\text { a TCDD }\end{array}$ & - & $\begin{array}{l}\text { Alteração na expressão de progesterona e desregulação da } \\
\text { fertilidade por três gerações, sem exposição adicional a qualquer } \\
\text { disruptor endócrino }\end{array}$ \\
\hline Cobellis et al. ${ }^{54}$ & $\begin{array}{l}\text { Mulheres com endometriose e } \\
\text { controles }\end{array}$ & Bisfenol A e B (bisfenol) & $\begin{array}{l}\text { Altas concentrações séricas de bisfenol A e B em mulheres com } \\
\text { endometriose e em nenhuma mulher do grupo controle }\end{array}$ \\
\hline Itoh et al. ${ }^{53}$ & $\begin{array}{l}\text { Mulheres com endometriose e } \\
\text { controles }\end{array}$ & Ftalatos & Nenhuma associação entre a endometriose e a exposição a ftalatos \\
\hline
\end{tabular}

TCDD: dioxina 2,3,7,8-tetraclorodibenzo-p-dioxina; DEHP: di-(2-etil-exil) ftalato. 
A exposição à progesterona durante a fase secretória do ciclo menstrual promove a regulação negativa das metaloproteinases endometriais, prevenindo, assim, o dano endometrial após a menstruação. Portanto, substâncias ambientais que interferem na ação da progesterona modificam o endométrio, promovendo um microambiente inflamatório semelhante ao processo de perda de tecido endometrial durante a menstruação. Enquanto a ação da progesterona sozinha pode tamponar certos processos inflamatórios na interface imunoendócrina do endométrio, não é surpreendente que a ação anti-inflamatória da progesterona também inclua a produção local de outros moduladores imunes importantes ${ }^{35}$.

Dada a habilidade do TCDD para inibir a expressão de progesterona e TGF-b2 no endométrio ${ }^{33}$, é possível que a exposição experimental a esse agente promova um microambiente endometrial mais inflamatório ${ }^{45}$. Entretanto, pouco se sabe sobre o impacto da exposição a esse agente na resposta aguda inflamatória, o que poderia desregular a função endometrial, levando ao desenvolvimento de doenças ${ }^{35}$.

Yang et al..$^{24}$ utilizaram um modelo de endometriose cirurgicamente induzido em macacos para investigar os efeitos da exposição ao TCDD no crescimento e sobrevivência do endométrio tópico. Fragmentos de endométrio foram autotransplantados para a cavidade pélvica de animais expostos cinco vezes por semana a doses de TCDD de $0,1,5$ e $25 \mathrm{ng} / \mathrm{kg}$ de peso/dia durante 12 meses. O crescimento e sobrevivência dos implantes foram verificados por laparoscopia nos meses 1, 3, 6 e 12 na fase lútea do ciclo menstrual. O tamanho e a sobrevivência dos implantes foram semelhantes entre os animais nos grupos expostos durante um, três e seis meses. O grupo exposto por 12 meses teve aumento da taxa de sobrevivência dos implantes, tanto na dose de 5 como de $25 \mathrm{ng}$, bem como um aumento do tamanho do fragmento nos animais com dose de $25 \mathrm{ng}$ de TCDD. As características do ciclo menstrual não foram alteradas em nenhum grupo.

Níveis séricos de TCDD e PCB foram analisados em macacos de 13 anos de idade após 4 anos de estudo, com exposição diária a 0,5 e $25 \mathrm{ng} / \mathrm{kg}$. Os níveis elevados de dioxina sérica foram correlacionados ao desenvolvimento de endometriose nesses animais ${ }^{24}$. Esses achados são relevantes em humanos, uma vez que os níveis séricos de TCDD registrados nos animais foram semelhantes às concentrações relatadas no soro, leite e tecidos da população em geral ${ }^{46}$.

Na Bélgica, Koninckx et al. ${ }^{47}$ observaram que a prevalência de endometriose em mulheres com infertilidade era de 60 a $80 \%$ e que as concentrações de TCDD no leite desse país está entre os mais altos do mundo ${ }^{48}$. Pauwels et al. ${ }^{23}$ conduziram um estudo caso-controle em mulheres belgas e encontraram um aumento da endometriose associada com elevados níveis séricos de dioxina e compostos derivados. Esse estudo forneceu uma das mais importantes evidências populacionais de que o desenvolvimento da endometriose pode estar relacionado à influência tóxica do TCDD.

Todavia, Eskenazi et al. ${ }^{49}$ estudaram 601 mulheres moradoras de Seveso, na Itália, que tiveram o soro coletado em 1976 após a explosão de uma indústria química, que resultou em exposição da população ao
TCDD. Vinte anos depois, os autores dosaram as concentrações séricas de TCDD e realizaram exames ginecológicos (ultrassom abdominal e transvaginal) e entrevista, que incluía questões como presença de dispareunia, dismenorreia, dor pélvica e história reprodutiva entre as participantes do estudo. As mulheres com alterações foram submetidas à laparoscopia e os resultados do estudo revelaram apenas 19 mulheres com endometriose. Os autores concluíram que não havia associação entre a exposição à dioxina e o desenvolvimento de endometriose.

Associação positiva entre a endometriose e a exposição à dioxina foi relatada em um estudo caso-controle em que 44 mulheres com endometriose foram comparadas a 35 controles com infertilidade tubária. Dezoito por cento das mulheres com endometriose e apenas 3\% das mulheres do grupo controle tiveram níveis detectáveis de dioxina no soro, uma diferença estatisticamente significante $(p=0,04)$. Neste estudo não foi observada relação entre a gravidade da endometriose e a concentração de dioxin $a^{50}$. Em outro estudo caso-controle, que estudou 86 mulheres com endometriose e 70 controles, nenhuma associação entre as concentrações plasmáticas de organoclorados e a endometriose foi encontrada $a^{51}$.

Concentrações plasmáticas de ftalatos foram associadas à endometriose em um estudo italiano, que sugeriu, pela primeira vez, a relação entre os ftalatos e a fisiopatologia da doença. Cobellis et al. ${ }^{52}$ estudaram as concentrações plasmáticas e peritoneais de DEHP (di(2-etil-exil) ftalato), composto do grupo dos ftalatos, em 55 mulheres com endometriose e 24 controles. Os resultados demonstraram que as mulheres com endometriose tinham concentrações maiores de DEHP no soro em relação ao controles $(p=0,004)$ e que $92,6 \%$ dessas tinham níveis aumentados de DEHP no fluido peritoneal. Nenhuma relação foi encontrada entre as concentrações de DEHP e o estágio da endometriose. Todavia, Itoh et al. ${ }^{53}$ estudaram a presença de metabólitos dos ftalatos em mulheres com queixa de infertilidade que foram submetidas a laparoscopia ( $n=57$ casos e $n=80$ controles) e os autores não encontraram qualquer relação entre os metabólitos dos ftalatos e o risco de desenvolvimento de endometriose nas mulheres japonesas $(p=0,73)$.

Cobellis et al. ${ }^{54}$ investigaram as concentrações séricas de bisfenol A e B no soro de 58 mulheres com endometriose e 11 mulheres férteis sem a doença. Altas concentrações de bisfenol A e B estavam presentes, respectivamente, em 51,7 e $27,6 \%$ das mulheres com endometriose e em nenhuma mulher do grupo controle. O composto bisfenol A e/ou B estava presente no soro de $63,8 \%$ das mulheres com endometriose, sugerindo importante relação entre a exposição ao bisfenol A ou B e a endometriose.

A interação entre o bisfenol A e/ou B com os receptores estrogênicos produz a ativação do mesmo fator de transcrição, o 17- $\beta$-estradiol ${ }^{55,56}$, localizado próximo à região promotora do gene da aromatase. Esse mecanismo, provavelmente, determina a atividade da aromatase e, consequentemente, a produção de estrogênio, favorecendo a proliferação e inflamação características da endometriose. Além disso, estudos prévios demonstraram relação entre concentrações séricas aumentadas 
de bisfenol A e seus metabólitos, secreção alterada de hormônios gonadotróficos e aumentos dos hormônios androgênicos ${ }^{57,58}$. O mecanismo pelo qual o bisfenol age não está totalmente claro, mas sabe-se que esse composto produz alteração no sistema endócrino que regula a proliferação, a diferenciação e a interação celular, provocando efeitos adversos na saúde humana ${ }^{54}$.

\section{Conclusão}

A endometriose é uma doença multifatorial de etiologia desconhecida até o presente momento. Recentemente, vários estudos têm associado a exposição a substâncias tóxicas ambientais na patogênese da doença. Essas substâncias, definidas como desreguladores endócrinos, são capazes de interagir com os receptores dos hormônios esteroides e mimetizar ou bloquear a resposta endócrina.

Pesquisas epidemiológicas dos efeitos dos desreguladores endócrinos na endometriose são difíceis de serem realizadas porque existem vários obstáculos. Um problema grave é a mistura de agentes diferen- tes com atividades estrogênicas, antiestrogênicas e antiandrogênicas potenciais no ambiente. Outra questão é o conhecimento limitado sobre o tempo entre a exposição e o efeito no organismo. Para a maioria dos efeitos adversos, a janela crítica de exposição (fase fetal, perinatal, puberdade ou adulta) ainda não foi identificada. Alguns estudos epidemiológicos relataram idade precoce da menarca associada com altos níveis de exposição pré-natal a DDE na prole de pescadores de Michigan ${ }^{59}$ e também aos ftalatos em Porto Rico ${ }^{60}$. Além disso, a pesquisa epidemiológica geralmente pode ser influenciada por fatores tais como a seleção da área de estudo, do tamanho de amostra, da escolha dos valores-limite, da substância estudada, entre outros.

Dessa forma, a relação entre os desreguladores endócrinos e a endometriose é complexa. O mecanismo exato de ação dos desreguladores endócrinos ainda não foi totalmente elucidado, mas acredita-se que essas substâncias possam levar à modificação epigenética e resultar em expressão gênica alterada. Mais estudos epidemiológicos e experimentais são necessários para esclarecer o real papel dos desreguladores endócrinos na fisiopatologia da endometriose.

\section{Referências}

1. Guyton AC, Hall JE. Tratado de Fisiologia Médica. ga ed. Rio de Janeiro: Guanabara Koogan; 1996.

2. Hombach-Klonisch S, Pocar P, Kietz S, Klonisch T. Molecular actions of polyhalogenated arylhydrocarbons (PAHs) in female reproduction. Curr Med Chem. 2005;12(5):599-616.

3. Caserta D, Maranghi L, Mantovani A, Marci R, Maranghi F, Moscarini M. Impact of endocrine disruptor chemicals in gynaecology. Hum Reprod Update. 2008;14(1):59-72.

4. Damstra T, Barlow S, Bergman A, Kavlock R, Der Kraak Van, International Programme on Chemical Safety. Global assessment of the state-of-thescience of endocrine disruptors [Internet]. World Health Organization; 2002. Disponível em: http://www.who.int/ipcs/publications/new issues/ endocrine_disruptors/en/

5. Mantovani A, Stazi AV, Macrì C, Maranghi F, Ricciardi C. Problems in testing and risk assessment of endocrine disrupting chemicals with regard to developmental toxicology. Chemosphere. 1999;39(8):1293-300.

6. Birkett JW, Lester JN. Endocrine Disrupters in Wastewater and Sludge Treatment Process.London: Lewis Publishers; 2003.

7. Guillette LJ Jr, Pickford DB, Crain DA, Rooney AA, Percival HF. Reduction in penis size and plasma testosterone concentrations in juvenile alligators living in a contaminated environment. Gen Comp Endocrinol. 1996;101(1):32-42.

8. Fernandez MA, Limaverde AM, Castro IB, Almeida ACM, Wagener ALR. Occurrence of imposex in Thais haemastoma: possible evidence of environmental contamination derived from organotin compounds in Rio de Janeiro and Fortaleza, Brazil. Cad Saúde Pública. 2002;18(2):463-76.

9. Koifman S, Koifman RJ, Meyer A. Human reproductive system disturbances and pesticide exposure in Brazil. Cad Saúde Pública. 2002;18(2):435-45.
10. Lemmen JG, Arends RJ, van der Saag PT, van der Burg B. In vivo imaging of activated estrogen in utero by estrogens and bisphenol A. Environ Health Perspect. 2004; 112(15):1544-9.

11. Bila DM, Dezotti M. Desreguladores endócrinos no meio ambiente: efeitos e conseqüências. Quím Nova. 2007;30(3):651-66.

12. Reys LL. Tóxicos ambientais desreguladores do sistema endócrino. Rev Facul Med Lisboa. 2001;6(1): 213-25.

13. Hartmann S, Lacorn M, Steinhart H. Natural occurrence of steroid hormones in food. Food Chem. 1998;62(1):7-20.

14. Peterson EW, Davis RK, Orndorff HA. $17 \beta$-Estradiol as an Indicator of Animal Waste Contamination in Mantled Karst Aquifers. J Environ Qual. 2000;29(3):826-34.

15. Renner SP, Strick R, Oppelt P, Fasching PA, Engel S, Baumann R et al. Evaluation of clinical parameters and estrogen receptor alpha gene polymorphisms for patient with endometriosis. Reproduction. 2006;131(1):153-61

16. Giudice LC, Kao LC. Endometriosis. Lancet. 2004;364(9447):1789-99.

17. Barbosa CP, de Souza AM, Bianco B, Christofolini DM, Mafra FA, de Lima GR. OC-125 immunostaining in endometriotic lesion samples. Arch Gynecol Obstet. 2009. [Epub ahead of print].

18. Barbosa CP, de Souza AM, Bianco B, Christofolini D, Bach FA, de Lima GR. Frequency of endometriotic lesions in peritoneum samples from asymptomatic fertile women and correlation with CA125 values. São Paulo Med J. 2009;127(6):342-5.

19. Marik JJ. Etiology-Current concepts in endometriosis: An intemational review. J Reprod Med. 1977;19(suppl):301-2. 
20. Garai J, Molnar V, Varga T, Koppan M, Torok A, Bodis J. Endometriosis: harmful survival of an ectopic tissue. Front Biosci. 2006;11:595-619.

21. Rier SE, Martin DC, Bowman RE, Dmowski WP, Becker JL. Endometriosis in rhesus monkeys (Macaca mulatta) following chronic exposure to 2,3,7,8-tetrachlorodibenzo-p-dioxin. Fundam Appl Toxicol. 1993;21(4): 433-41.

22. Heindel JJ, McAllister KA, Worth L Jr, Tyson FL. Environmental epigenomics, imprinting and disease susceptibility. Epigenetics. 2006;1(1):1-6.

23. Pauwels A, Schepens PJ, D'Hooghe T, Delbeke L, Dhont M, Brouwer A et al. The risk of endometriosis and exposure to dioxins and polychlorinated biphenyls: a case-control study of infertile women. Hum Reprod. 2001;16(10):2050-5.

24. Yang JZ, Agarwal SK, Foster WG. Subchronic exposure to 2,3,7,8-tetrachlorodibenzo-p-dioxin modulates the pathophysiology of endometriosis in the cynomolgus monkey. Toxicol Sci. 2000;56(2):374-81.

25. Rier S, Foster WG. Environmental dioxins and endometriosis. Toxicol Sci. 2002;70(2):161-70.

26. Heimler I, Rawlins RG, Owen H, Hutz RJ. Dioxin perturbs, in a dose- and time-dependent fashion, steroid secretion, and induces apoptosis of human luteinized granulosa cells. Endocrinology. 1998;139(10):4373-9.

27. Morán FM, VandeVoort CA, Overstreet JW, Lasley BL, Conley AJ. Molecular target of endocrine disruption in human luteinizing granulosa cells by 2,3,7,8-tetrachlorodibenzo-p-dioxin: inhibition of estradiol secretion due to decreased 17alpha-hydroxylase/17,20-lyase cytochrome P450 expression. Endocrinology. 2003;144(2):467-73.

28. Pocar P, Fischer B, Klonisch T, Hombach-Klonisch S. Molecular interactions of the aryl hydrocarbon receptor and its biological and toxicological relevance for reproduction. Reproduction. 2005;129(4):379-89.

29. Zhao D, Pritts EA, Chao VA, Savouret JF, Taylor RN. Dioxin stimulates RANTES expression in an in-vitro model of endometriosis. Mol Hum Reprod. 2002;8(9):849-54.

30. Pande K, Moran SM, Bradfield CA. Aspects of dioxin toxicity are mediated by interleukin 1-like cytokines. Mol Pharmacol. 2005;67(5):1393-8.

31. Shi YL, Luo XZ, Zhu XY, Hua KQ, Zhu Y, Li DJ. Effects of combined 17betaestradiol with TCDD on secretion of chemokine IL-8 and expression of its receptor CXCR1 in endometriotic focus-associated cells in co-culture. Hum Reprod. 2006;21(4):870-9.

32. Osteen KG, Bruner-Tran KL, Eisenberg E. Reduced progesterone action during endometrial maturation: a potential risk factor for the development of endometriosis. Fertil Steril. 2005;83(3):529-37.

33. Igarashi TM, Bruner-Tran KL, Yeaman GR, Lessey BA, Edwards DP, Eisenberg $E$ et al. Reduced expression of progesterone receptor- $B$ in the endometrium of women with endometriosis and in cocultures of endometrial cells exposed to 2,3,7,8-tetrachlorodibenzo-p-dioxin. Fertil Steril. 2005;84(1):67-74.

34. Nayyar T, Bruner-Tran KL, Piestrzeniewicz-Ulanska D, Osteen KG. Developmental exposure of mice to TCDD elicits a similar uterine phenotype in adult animals as observed in women with endometriosis. Reprod Toxicol. 2007;23(3):326-36.
35. Bruner-Tran KL, Yeaman GR, Crispens MA, Igarashi TM, Osteen KG. Dioxin may promote inflammation-related development of endometriosis. Fertil Steril. 2008;89(5 Suppl):1287-98.

36. Attia GR, Zeitoun K, Edwards D, Johns A, Carr BR, Bulun SE. Progesterone receptor isoform $A$ but not $B$ is expressed in endometriosis. J Clin Endocrinol Metabol. 2000;85(8):2897-902.

37. Bulun SE, Cheng YH, Yin P, Imir G, Utsunomiya H, Attar E et al. Progesterone resistance in endometriosis: link to failure to metabolize estradiol. Mol Cell Endocrinol. 2006;248(1-2):94-103.

38. Majewski AC, Hansen PJ. Progesterone inhibits rejection of xenogeneic transplants in the sheep uterus. Horm Res. 2002;58(3):128-35.

39. Mendelson CR, Hardy DB. Role of the progesterone receptor (PR) in the regulation of inflammatory response pathways and aromatase in the breast. J Steroid Biochem Mol Biol. 2006;102(1-5):241-9.

40. Braun DP, Dmowski WP. Endometriosis: abnormal endometrium and dysfunctional immune response. Curr Opin Obstet Gynecol. 1998;10(5): 365-9.

41. Iborra A, Palacio JR, Ulcova-Gallova Z, Martínez P. Autoimmune response in women with endometriosis. Am J Reprod Immunol. 2000;44(4): 236-41.

42. Maeda N, Izumiya $\mathrm{C}$, Oguri $\mathrm{H}$, Kusume T, Yamamoto $\mathrm{Y}$, Fukaya T. Aberrant expression of intercellular adhesion molecule-1 and killer inhibitory receptors induces immune tolerance in women with pelvic endometriosis. Fertil Steril. 2002;77(4):679-83

43. Yeaman GR, Collins JE, Lang GA. Autoantibody responses to carbohydrate epitopes in endometriosis. Ann NY Acad Sci. 2002;955: 174-82.

44. Matarese G, De Placido G, Nikas Y, Alviggi C. Pathogenesis of endometriosis: natural immunity dysfunction or autoimmune disease? Trends Mol Med. 2003;9(5):223-8.

45. Osteen KG, Keller NR, Feltus FA, Melner MH. Paracrine regulation of matrix metalloproteinase expression in the normal human endometrium. Gynecol Obstet Invest. 1999;48 Suppl 1:2-13.

46. Rier SE, Turner WE, Martin DC, Morris R, Lucier GW, Clark GC. Serum levels of TCDD and dioxin-like chemicals in Rhesus monkeys chronically exposed to dioxin: correlation of increased serum PCB levels with endometriosis. Toxicol Sci. 2001;59(1):147-59.

47. Koninckx PR, Braet P, Kennedy SH, Barlow DH. Dioxin pollution and endometriosis in Belgium. Hum Reprod. 1994;9(6):1001-2.

48. [No authors listed]. Assessment of the health risk of dioxins: re-evaluation of the tolerable daily intake (TDI). Geneva, Switzerland, 25-29 May 1998. Food Addit Contam. 2000;17(4):223-369.

49. Eskenazi B, Mocarelli P, Warner M, Samuels S, Vercellini P, Olive D et al. Serum dioxin concentrations and endometriosis: a cohort study in Seveso, Italy. Environ Health Perspect. 2002;110(7):629-34.

50. Mayani A, Barel S, Soback S, Almagor M. Dioxin concentrations in women with endometriosis. Hum Reprod. 1997;12(2):373-5. 
51. Lebel G, Dodin S, Ayotte P, Marcoux S, Ferron LA, Dewailly E. Organochlorine exposure and the risk of endometriosis. Fertil Steril. 1998;69(2): 221-8.

52. Cobellis L, Latini G, De Felice C, Razzi S, Paris I, Ruggieri F et al. High plasma concentrations of di-(2-ethylhexy)-phthalate in women with endometriosis Hum Reprod. 2003;18(7):1512-5.

53. Itoh H, Iwasaki M, Hanaoka T, Sasaki H, Tanaka T, Tsugane S. Urinary phthalate monoesters and endometriosis in infertile Japanese women. Sci Total Environ. 2009;408(1):37-42.

54. Cobellis L, Colacurci N, Trabucco E, Carpentiero C, Grumetto L. Measurement of bisphenol $\mathrm{A}$ and bisphenol $\mathrm{B}$ levels in human blood sera from healthy and endometriotic women. Biomed Chromatogr. 2009;23(11): $1186-90$.

55. Tinwell H, Joiner R, Pate I, Soames A, Foster J, Ashby J. Uterotrophic activity of bisphenol $\mathrm{A}$ in the immature mouse. Regul Toxicol Pharmacol. 2000;32(1):118-26
56. Quesada I, Fuentes E, Viso-León MC, Soria B, Ripoll C Nadal A Low doses of the endocrine disruptor bisphenol-A and the native hormone 17beta-estradiol rapidly activate transcription factor CREB. FASEB J. 2002;16(12):1671-3.

57. Takeuchi T, Tsutsumi 0, Ikezuki Y, Takai Y, Taketani Y. Positive relationship between androgen and the endocrine disruptor, bisphenol $A$, in normal women and women with ovarian dysfunction. Endocr J. 2004;51(2):165-9.

58. Takeuchi T, Tsutsumi 0, Ikezuki Y, Kamei Y, Osuga Y, Fujiwara T et al. Elevated serum bisphenol A levels under hyperandrogenic conditions may be caused by decreased UDP-glucuronosyltransferase activity. Endocrine J. 2006;53(4):485-91.

59. Vasiliu 0, Muttineni J, Karmaus W. In utero exposure to organochlorines and age at menarche. Hum Reprod. 2004;19(7):1506-12.

60. Colón I, Caro D, Bourdony CJ, Rosario 0. Identification of phthalate esters in the serum of young Puerto Rican girls with premature breast development. Environ Health Perspect. 2000;108(9):895-900. 